\title{
A violência sexual contra crianças e adolescentes: conhecer a realidade possibilita a ação protetiva'
}

\author{
Sexual abuse of children and adolescents: understanding \\ the reality enables protective action
}

\author{
Viviane Amaral dos SANTOS ${ }^{2}$ \\ Liana Fortunato $\operatorname{COSTA}^{3}$
}

\begin{abstract}
Resumo
Trata-se de pesquisa exploratória realizada no contexto da 1a Vara da Infância e Juventude do Distrito Federal. O objetivo do trabalho foi avaliar o cumprimento das medidas protetivas aplicadas pelo juiz às crianças e aos adolescentes envolvidos em situação de violência sexual. Os dados foram coletados por meio de consulta documental, contatos telefônicos com as instituições responsáveis pela execução das medidas protetivas determinadas e com 25 delegacias circunscricionais. No âmbito da situação de violência sexual, os dados revelaram que os abusos ocorreram dentro de casa e foram cometidos por parentes próximos. As vítimas eram majoritariamente do gênero feminino, entre três e oito anos. No que toca à garantia de proteção integral, constatou-se desconexão entre as instituições do sistema de proteção. O trabalho em rede mostrou-se necessário para a devida proteção de crianças e adolescentes em situação de violência sexual, e fator relevante na construção de políticas públicas voltadas para a prevenção e intervenção.
\end{abstract}

Palavras chave: Abuso sexual. Direitos humanos. Justiça. Justiça social.

\begin{abstract}
This text presents the results of research carried out in the Infancy and Youth Courts in Brasilia, Brazil. The aim of the research was to evaluate the enforcement of the protective measures applied by the Judge to child and adolescent victims. The method included documentary analysis; telephone contact with the institutions responsible for carrying out the protective measures judicially applied; telephone contact with 25 police departments in Brasilia. The results showed that sexual abuse occurs in the home and is perpetrated by close relatives. The main victims are girls between the ages of three and eight. It also showed that there is a disconnect in the actions taken by the agencies of the legal and protective system. The results showed that the effectiveness of the protective action depends on the establishment of a network that promotes connectedness and partnership between the legal and care organizations. It also represents a significant contribution to the construction of public policies focusing on prevention and intervention with regard to sexual abuse.
\end{abstract}

Uniterms: Sexual abuse. Human rights. Justice. Social justice.

$\boldsymbol{\nabla} \mathbf{V} \boldsymbol{\nabla}$

1 Artigo elaborado a partir da tese de V.A. SANTOS, intitulada "As medidas protetivas e a garantia de direitos na percepção de famílias em situação de violência sexual". Universidade de Brasília, 2010.

2 1a Vara da Infância e da Juventude do Distrito Federal, Centro de Referência para Violência Sexual. SGAN 909, Blocos D/E, Asa Norte, 70770-530, Brasília, DF, Brasil. Correspondência para/Correspondence to: V.A. SANTOS. E-mail: < viviane.santos@tjdft.jus.br>.

3 Universidade de Brasília, Instituto de Psicologia, Programa de Pós-Graduação em Psicologia Clínica e Cultura. Brasília, DF, Brasil. 
Este texto apresenta os resultados de uma pesquisa exploratória realizada na 1a Vara da Infância e Juventude do Distrito Federal e Territórios - 1a VIJ/DF, que teve como objetivo avaliar os aspectos de resolubilidade das ações de enfrentamento da violência sexual, seja no âmbito legal, seja na esfera de prevenção, responsabilização e/ou de atendimento às vítimas e familiares. Assim, procurou-se conhecer/avaliar os caminhos de resolução do processo. Buscou-se ampliar o entendimento de que, apesar de todos os esforços empreendidos para interrupção do ciclo da violência, a intervenção profissional e institucional pode, de forma contrária a seu objetivo, reproduzir, por meio de ações desconexas ou ausência de ações efetivas, a violência emocional e organizacional, conforme alertam vários autores (Azambuja, 2004, Azevedo \& Guerra, 1997; E. Faleiros, 2003; V.F. Faleiros \&E.T.S. Faleiros, 2001; Furniss, 1993). Necessita-se melhor compreender como o isolamento e a fragmentação que caracterizam as intervenções profissionais e institucionais não têm conseguido, assim como as famílias em situação de violência sexual, oferecer o necessário apoio e proteção às crianças e adolescentes que delas necessitam.

Segundo Sanderson (2005, p.17), a violência sexual contra crianças e adolescentes é definida como

O envolvimento de crianças e adolescentes dependentes em atividades sexuais com um adulto ou com qualquer pessoa um pouco mais velha ou maior, em que haja uma diferença de idade, de tamanho ou de poder, em que a criança é usada como objeto sexual para a gratificação das necessidades ou dos desejos, para a qual ela é incapaz de dar um consentimento consciente por causa do desequilíbrio no poder, ou de qualquer incapacidade mental ou física. Essa definição exclui atividade consensual entre colegas.

Essa definição destaca os seguintes elementos relacionais: diferença de idade entre agressor e vítima, denotando a desigualdade presente na relação; o lugar de objeto da criança para satisfação de um desejo sexual que é tão somente do adulto; e a impossibilidade da criança oferecer consentimento informado, em razão da desigualdade de poder ou da condição mental. Tal definição também indica o entendimento de que a violência sexual contra crianças e adolescentes está situada no campo das relações sociais e familiares, com

530 fortes componentes culturais e de valores.
Somam-se a isso os aspectos socioeconômicos que, apesar de não serem determinantes e de não limitarem a ocorrência da violência sexual às classes menos favorecidas, agregam maior complexidade ao fenômeno, promovendo maiores prejuízos além daqueles provocados pela situação sexualmente abusiva. As ações de proteção, então, devem focalizar a imediata resolubilidade dos casos, com o objetivo de dirimir os efeitos nefastos da violência sexual e das condições contextuais que ampliam a condição de vulnerabilidade das crianças e adolescentes vítimas.

Por resolubilidade entende-se não apenas a garantia do direito ao respeito, dignidade, liberdade, convivência familiar e comunitária e desenvolvimento de uma sexualidade saudável, conforme preconizado pelo Estatuto da Criança e do Adolescente (ECA) e outros acordos internacionais. Por resolubilidade, segundo V.F. Faleiros e E.T.S. Faleiros (2001), toma-se também o adequado e satisfatório atendimento de todos os direitos violados na situação que se instala após a revelação da violência sexual. Os direitos violados e a serem resgatados podem variar de caso para caso, mas quando a violência se instala em um contexto economicamente desfavorecido, em geral incluem o direito ao atendimento das necessidades básicas - tais como moradia, alimentação, lazer, educação, entre outros -, que podem ser afetadas quando o agressor é o único provedor da família, por exemplo.

Habigzang, Koller, Azevedo e Machado (2005) mostram como mudam as condições de sobrevivência das famílias após a denúncia da violência sexual, em especial daquelas menos favorecidas economicamente. A configuração familiar se modifica porque há a saída ou a entrada de pessoas na tentativa de proteger a criança, ou esta é deslocada para viver em situação na qual outro adulto se responsabiliza por sua proteção. A condição financeira se altera principalmente quando o agressor é também provedor (o pai, por exemplo), e é recolhido ao sistema penal ou judicialmente afastado do grupo familiar. Essa situação leva a um paradoxo, pois após a denúncia e o afastamento da pessoa que se constituía no perigo para a segurança da criança, a família pode ampliar uma situação de vulnerabilidade.

Costa, Penso, Mendes e Borba (2007) também chamam atenção para o que ocorre com as famílias durante o período compreendido entre a ocorrência da denúncia e o momento no qual se iniciam os atendi- 
mentos terapêuticos (quando é possível). Tanto as famílias como as crianças e os adolescentes violentados permanecem em silêncio, ocultando sua dor, afastando-se de seus pares e vivenciando intenso sofrimento sem a devida significação e valorização do que se passou e está se passando.

Esse quadro pode levar a vítima a se retratar, provocando grande confusão nas pessoas envolvidas vítima, familiares, sistema legal e de tratamento, pois coloca a palavra da criança ou do adolescente em dúvida e mascara a real ocorrência das situações de violência sexual, assim como suas implicações (V.P. Faleiros \& E.T.S. Faleiros, 2001). Observa-se, então, como é fundamental conhecer em profundidade a realidade das crianças, adolescentes e famílias em situação de violência sexual, para que se possa pensar e planejar ações de efetiva proteção.

Os resultados obtidos na pesquisa não se diferenciam, mas corroboram os resultados de várias outras pesquisas já realizadas (Azambuja, 2004; Azevedo \& Guerra, 1997; E. Faleiros, 2003; V.P. Faleiros \& E.T.S. Faleiros, 2001; Save the Children Suécia, 2005). Esses autores revelam que, apesar da existência de várias instituições de enfrentamento ao abuso sexual (Delegacias, Delegacias de Proteção à Criança e ao Adolescente, Varas da Infância e Juventude, Conselhos Tutelares, Centros de Referência em Assistência Social, Serviços de Atendimento à saúde física e mental em hospitais públicos, programas governamentais, entre outros), as pessoas em situação de violência sexual percorrem um difícil caminho, que se inicia com a própria ocorrência do abuso, mas que pode não se encerrar, necessariamente, com a revelação e denúncia. Após a notificação, as famílias podem transitar entre várias instituições, recebendo duplicidade ou sofrendo a interrupção das ações porventura já iniciadas.

A ausência de articulação entre as instituições promove o que se chama de revitimização, submetendo as pessoas envolvidas em situação de violência sexual a um padrão de organização interinstitucional fragmentado e compartimentalizado. Dessa forma, dificulta-se ou impede-se "a mudança das condições objetivas, culturais e subjetivas que geram, mantêm ou facilitam a dinâmica e a ameaça abusiva" (V.P. Faleiros \& E.T.S. Faleiros, 2001, p.25).

\section{Método}

A pesquisa foi realizada na 1a Vara da Infância e Juventude, cuja missão é garantir os direitos de crianças e adolescentes, por meio da prestação jurisdicional, assegurando-Ihes condições para o pleno desenvolvimento individual e social, com fundamento na Lei 8.069/90 - Estatuto da Criança e do Adolescente. Quando provocado, e quando confirmada a denúncia, o Magistrado da $1^{\text {a }}$ VIJ atua na aplicação de medidas judiciais protetivas, tais como afastamento do agressor do lar, suspensão de visitas, encaminhamento para tratamento de saúde física ou mental, orientação, assistência social, abrigamento, entre outras.

\section{Participantes}

Os sujeitos foram as histórias de violência sexual contidas nas 47 Pastas Especiais autuadas na $1^{\text {a }}$ VIJ no ano de 2006. Pastas Especiais são procedimentos de acompanhamento de crianças e/ou adolescentes em situação de risco, com vistas à aplicação dos artigos 101, 129 e 130 da Lei 8.069/90 - Estatuto da Criança e do Adolescente. As Pastas Especiais são constituídas por petições apresentadas pela Defensoria Pública ou advogados das partes envolvidas, manifestações do Ministério Público, relatórios técnicos de psicólogos e/ou assistentes sociais que realizaram estudo psicossocial dos casos, relatórios de entrevistas na Delegacia de Proteção à Criança e ao Adolescente ou outra delegacia, laudos do Instituto Médico Legal, entre outros documentos.

Para complementação das informações contidas nas Pastas Especiais, foram realizados contatos telefônicos com os coordenadores das instituições responsáveis pelo cumprimento das medidas protetivas aplicadas pelo magistrado nas 40 Pastas: 6 Centro de Referência de Assistência Social da Secretaria de Desenvolvimento Social e Transferência de Renda do Governo do Distrito Federal (CREAS), 8 Conselhos Tutelares, 1 Clínica de Psicologia Universitária e 1 profissional autônomo de Psicologia. Ressalta-se que uma mesma família pode ser encaminhada para mais de uma instituição, de acordo com as demandas apresentadas.

Também foram contatadas, por telefone, 25 delegacias circunscricionais do Distrito Federal, com o objetivo de se avaliar se as ações de investigação e respon- 
sabilização se conjugavam com ações de proteção, isto é, se o procedimento adotado por elas envolvia o encaminhamento dos casos notificados para as instâncias do sistema de proteção integral, tais como os Conselhos Tutelares e/ou a 1 a VIJ. Neste caso, o contato foi realizado com os delegados titulares ou substitutos.

\section{Instrumentos e Procedimentos}

Foi criada uma planilha padronizada, na qual foram registrados os seguintes indicadores:

1) no âmbito de análise da situação de violência sexual: idade e gênero das vítimas, autores da violência sexual, contexto em que ocorreu a violência sexual, tipos de abuso sexual, contexto socioeconômico. No presente texto, porém, será apresentado apenas o perfil das vítimas e autores da violência sexual;

2) no âmbito da garantia de proteção integral: Tipos de medida protetiva aplicada; número de encaminhamentos para instituições de cumprimento das medidas protetivas determinadas judicialmente; índice de cumprimento das medidas protetivas; observações quanto ao cumprimento das medidas protetivas.

Esses indicadores foram registrados de acordo com a frequência e intervalo de tempo das ações da rede de defesa e proteção. As respostas foram registradas segundo sua condição de afirmativas ou negativas, e foi realizada, então, uma média simples dessas respostas em relação ao número de instituições contatadas. Quanto ao fator que motivava o encaminhamento dos casos pelas delegacias circunscricionais para a rede de proteção e garantia de direitos, foram avaliados os temas mais recorrentes e registrados como frequências, sendo que a maior parte informou"não fazer parte do procedimento padrão o encaminhamento do caso" para instituições de proteção.

Com os CREAS, Conselhos Tutelares, Clínica universitária e profissional autônomo de Psicologia, os contatos telefônicos ocorreram com o objetivo de verificar se as medidas protetivas determinadas judicialmente haviam sido cumpridas, através das seguintes questões: Vocês receberam ofício com determinação judicial para atendimento à criança (nome da criança)? A ação determinada neste caso foi cumprida? Em caso afirmativo,

532 especificar a ação e resultados. Em caso negativo, infor- mar as razões para o não cumprimento da medida protetiva determinada.

Com as delegacias circunscricionais, as questões foram: Há registro de denúncias de violência sexual contra crianças e adolescentes? Faz parte do procedimento dessa delegacia encaminhar as denúncias para o Conselho Tutelar ou para a Vara da Infância e da Juventude para aplicação de medidas protetivas? Em caso afirmativo, quantas denúncias de violência sexual contra crianças e adolescentes foram encaminhadas ao Conselho Tutelar ou à 1 a VIJ no período de $1^{\circ}$ de janeiro a 31 de dezembro de 2006? Faz parte do procedimento da delegacia encaminhar as pessoas envolvidas em situação de violência sexual para outras instituições de atendimento na comunidade? Em caso afirmativo, para quais instituições? Que tipo(s) de situação(ões) moti$\mathrm{va}(\mathrm{m})$ tal encaminhamento?

Os dados foram quantificados por categorias, a serem apresentadas nos resultados.

Os profissionais participantes foram informados sobre a finalidade da pesquisa e a forma de envolvimento que nela teriam, bem como sobre a liberdade de não participarem. Esta pesquisa faz parte do Doutoramento da primeira autora, sob orientação da segunda, tendo sido submetida ao Comitê de Ética do Instituto de Ciências Humanas da Universidade de Brasília, aprovado em 27/3/2009. Também foi autorizada pelo Juiz Titular da 1a VIJ/DF.

\section{Resultados e Discussão}

Considera-se que os aspectos aqui abordados não constituem a totalidade, nem abrangem toda a complexidade do trabalho de intervenção legal, social e de saúde, desafiando o leitor a apresentar outras questões complementares ou divergentes que, certamente, enriquecerão a discussão apresentada.

\section{No âmbito da análise da situação de violência sexual}

O sexo fragilizado: Nos 40 casos estudados, 47 crianças e/ou adolescentes foram vítimas de violência sexual. O número de criança é maior do que o número de Pastas Especiais, por haver, em alguns casos, mais de 
uma criança ou adolescente vítima na mesma família. Das 47 crianças, 41 (87,2\%) eram do sexo feminino, e 6 $(12,8 \%)$ do masculino.

A infância suscetível: Conforme se pode verificar a seguir, a infância, objeto de proteção da família, da sociedade e do Estado, conforme promulgado na Constituição da República (Brasil, 1988) e no Estatuto da Criança e do Adolescente (Brasil, 1990), instrumentos que regem as ações e intervenções das instituições sociais, é o alvo principal da violência sexual. No intuito de se compreender em que faixa etária as 47 crianças se encontravam quando foram vitimizadas, optou-se por subdividir as idades em intervalos (Tabela 1).

Das 47 crianças em situação de violência sexual, os dois maiores índices se encontravam nas faixas etárias de 3 a 5 anos, e de 6 a 8 anos (23,4\% e 27,6\%, respectivamente), indicando a infância como período de maior suscetibilidade.

Os autores da violência sexual: Dentre os 41 agressores registrados, 17 eram os pais, e 10 os padrastos. Isto é, as pessoas que deveriam desempenhar a função parental revelaram-se o maior algoz das crianças que dependem de sua proteção para o saudável desenvolvimento psicossocial, seguidas de "outros familiares" (9), como avô (3) e namorado da mãe (2). Esses resultados são coerentes com os dados estatísticos da $1^{\text {a } ~ V I J / D F, ~}$ que indicam a maior frequência do pai como agressor. Das 26 crianças, 6 residiam com a mãe e o pai na época em que sofreram violência, 13 residiam na companhia da mãe e do padrasto, 4 moravam apenas com a mãe, e outras 3 viviam com outros familiares.

A experiência de violência sexual com as figuras parentais pode se constituir uma das mais estressoras e

Tabela 1. Idade das crianças e adolescentes em situação de violência sexual.

\begin{tabular}{lcc}
\hline \multirow{2}{*}{ Faixa Etária (ano) } & \multicolumn{2}{c}{ Sujeitos } \\
\cline { 2 - 3 } & $n$ & $\%$ \\
\hline $0 \vdash 2$ & 2 & 4,3 \\
$3 \vdash 5$ & 11 & 23,4 \\
$6 \vdash 8$ & 13 & 27,6 \\
$9 \vdash 11$ & 8 & 17,0 \\
$12 \vdash 15$ & 11 & 23,4 \\
$16 \vdash 18$ & 2 & 4,2 \\
\hline Total & 47 & 100,0 \\
\hline
\end{tabular}

traumáticas experiências de um indivíduo, pois os posiciona entre a confiança e a insegurança, entre o amor e o ódio, entre o prazer e a repulsa (Azambuja, 2004; Furniss, 1993; Lamour, 1997; Nogueira \& Sá, 2004; Rouyer, 1997). As consequências observadas nos estudos psicossociais e reportadas nos Relatórios Técnicos contidos nas Pastas Especiais analisadas incluem desde sentimentos de baixa autoestima, culpa e vergonha, até dificuldade em desenvolver relacionamentos de confiança.

Além dessas consequências, Rouyer (1997) aponta a somatização, a confusão emocional e até a reprodução da situação vivenciada por meio de comportamentos delinquentes, prostituição, dentre inúmeros outros. Tais comportamentos ou sintomas podem ainda acarretar mais sofrimento, pois, ao invés de serem compreendidos como uma forma de lidar e reagir ao sofrimento ou como um pedido de socorro, acabam por invalidar a palavra da criança ou adolescente, podendo até servir aos olhos de terceiros como justificativa para a violência sofrida e como forma de desqualificar a sua queixa (Amaro, 2003).

\section{No âmbito da garantia de proteção integral}

Consideram-se, a seguir, as ações de proteção integral desenvolvidas pelos profissionais e instituições, desde a denúncia até o cumprimento das medidas protetivas, quando estas são aplicadas. Novamente, ressalta-se que para orientar essa discussão toma-se como princípio o fato de que a resolubilidade não se resume à responsabilização do agressor e atendimento psicológico à vítima, mas envolve a reparação da violência sofrida, a proteção física e social à criança/adolescente, e a garantia da defesa dos direitos violados na situação de violência sexual e, principalmente, dos direitos violados no contexto que se instala após a revelação da violência sofrida.

O Conselho Tutelar é o órgão competente para aplicação das medidas protetivas nos casos de violação dos direitos da infância e da juventude. No entanto, quando há necessidade de aplicação de medidas judiciais de proteção, o caso é encaminhado à Vara da Infância e da Juventude, que, além das medidas judiciais pertinentes, quando estas se fazem necessárias, pode aplicar as medidas previstas nos artigos 101 e 129 do ECA. 
Nesse sentido, a 1a VIJ tem como missão "garantir os direitos da criança e do adolescente, no âmbito do Distrito Federal, por meio da prestação jurisdicional, assegurando-Ihes condições para o seu pleno desenvolvimento pessoal e social". Tal prerrogativa posiciona a Instituição no sistema de proteção integral, em conexão e colaboração mútua e recíproca com todas as outras instâncias que fazem parte do circuito de enfrentamento à violência sexual.

O que acontece no âmbito da 1a VIJ: A denúncia oferecida por qualquer instância ocasiona a autuação imediata de procedimento administrativo de avaliação do caso. O trâmite, desde a autuação até o encaminhamento de ofício para cumprimento das medidas protetivas determinadas pelo juiz, leva 4 meses, em média. Porém, a esse tempo somam-se os quase 3 meses entre a denúncia e a autuação da pasta especial, o que resultará num intervalo médio de 7,4 meses entre a denúncia e a determinação da medida protetiva pertinente ao caso. Vale ainda notar que a esse intervalo de tempo soma-se aquele relacionado ao atendimento efetivo pelo órgão de proteção indicado, muitas vezes com demanda abarrotada e sem capacidade de dar uma resposta eficaz às necessidades apresentadas pela família.

O longo lapso temporal entre a denúncia e a ação protetora pode favorecer a retratação da vítima, pois passada a crise da revelação e da denúncia, a família tende a"esquecer" ou minimizar o ocorrido, como forma de se proteger do sofrimento. Por vezes, também, a família se dá conta das consequências judiciais para o agressor, o que faz com que se arrependa de ter realizado a denúncia.

A la VIJ garante os direitos das crianças e adolescentes e assegura as condições para seu pleno desenvolvimento? É importante considerar que a determinação judicial e o encaminhamento do ofício para cumprimento das medidas protetivas não significam o fim do processo de acompanhamento da criança ou adolescente em situação de risco. Muitas vezes, o ofício é encaminhado a outras instituições solicitando maiores informações, e o que se observa é que as respostas nem sempre são imediatas, podendo comprometer a eficácia do trabalho que pretende ser protetivo. Mais importante ainda é considerar que a autuação de Pasta Especial, a realização de estudo psicossocial, a determinação judicial de medidas protetivas e o encaminhamento de

534 ofício para seu cumprimento são apenas uma parte de um longo processo que está longe de se acabar para as famílias e para que se "garantam os direitos da criança e do adolescente e para que se Ihes assegurem as condições para o seu pleno desenvolvimento".

Nesse processo, a 1a VIJ é apenas um ponto de uma rede desconexa e desarticulada. O órgão realiza encaminhamentos a várias instituições sociais e de saúde, tais como hospitais e CREAS, onde as pessoas em situação de violência sexual deveriam receber as medidas protetivas. No entanto, essas instituições encontram-se sobrecarregadas pelo volume de trabalho e pela escassez de recursos humanos, financeiros e logísticos (Tabela 2).

Ao mesmo tempo que todas as instituições lutam contra os obstáculos e dificuldades e tentam contribuir para efetivar as medidas protetivas, também produzem a revitimizaçao das pessoas envolvidas em situação de violência sexual, seja pela repetição de ações, seja pela descontinuidade do acompanhamento de seus clientes, seja ainda pela demora no atendimento. Apesar disso, considera-se que a $1^{\text {a }}$ VIJ, por sua especificidade de prestação jurisdicional, não pode prescindir da contribuição dessas instituições. Os dados da pesquisa, apresentados no próximo item, revelam a necessidade urgente de se repensar o método de trabalho da 1 a VIJ e das instituições, e, em especial, de se repensar a relação estabelecida entre essas instituições.

As medidas protetivas protegem? Medidas protetivas são uma forma de garantir que os direitos violados sejam resgatados, fortalecendo, assim, o sistema familiar, para sua rápida reorganização. As medidas protetivas estão elencadas na Lei 8.069/90, nos Artigos 101, 129 e 130, e devem ser aplicadas "sempre que os direitos reconhecidos nesta lei forem ameaçados ou violados:

Tabela 2. Instituições de cumprimento das medidas protetivas.

\begin{tabular}{lc}
\hline $\begin{array}{l}\text { Instituições demandadas para } \\
\text { desenvolver ações protetivas }\end{array}$ & $\begin{array}{c}\text { Medidas sugeridas para as } \\
\text { instituições }(n \neq 88)\end{array}$ \\
\hline CREAS & 14 \\
Conselhos Tutelares & 20 \\
Clínicas Universitárias & 5 \\
Hospitais Públicos & 11 \\
Prof. Liberais/Clínicas & 10 \\
COMPP & 0 \\
Outros & 28 \\
\hline
\end{tabular}

CREAS: centro de referência especializado em assistência social; COMPP: centro de orientação médico psico-pedagógico. 
I - por ação ou omissão da sociedade ou do Estado; Il - por falta, omissão o abuso dos pais ou responsáveis; III - em razão de sua conduta" (Brasil, 1990).

Nos casos avaliados, as medidas protetivas determinadas pelo magistrado se distribuíram nas áreas da saúde mental (30), assistência social (33) e legal (25).

As medidas protetivas são aplicáveis às crianças e adolescentes, e também aos pais e responsáveis.

As medidas protetivas na área da saúde compreendem: requisição de tratamento médico, psicológico ou psiquiátrico, em regime hospitalar ou ambulatorial; inclusão em programa oficial ou comunitário de auxílio, orientação e tratamento a alcoólatras e toxicômanos (Artigos 101 e 129) (Brasil, 1990).

Na área social, as medidas protetivas envolvem: encaminhamento aos pais ou responsável, mediante termo de responsabilidade; orientação, apoio e acompanhamento temporários; inclusão em programa comunitário ou oficial de auxílio à família, à criança e ao adolescente; encaminhamento a cursos ou programas de orientação; obrigação de matricular o filho ou pupilo e acompanhar sua frequência e aproveitamento escolar; obrigação de encaminhar a criança ou adolescente a tratamento especializado; advertência (Artigos 101 e 129) (Brasil, 1990).

No âmbito legal, as medidas protetivas compreendem: abrigo em entidade; colocação em família substituta (Art. 101). E, ainda, conforme o Art. 130, verificada a hipótese de maus-tratos, opressão ou abuso sexual impostos pelos pais ou responsável, a autoridade judiciária poderá determinar, como medida cautelar, o afastamento do agressor da moradia comum (Brasil, 1990).

Entende-se que, para que o processo de recuperação e restauração seja eficaz, é necessário uma ágil e correta compreensão da situação, bem como a administração imediata de medidas pertinentes. O que se observa, no entanto, é um quadro bastante diferente. No universo das 40 Pastas Especiais pesquisadas, foram sugeridas 88 medidas protetivas pelos profissionais de psicologia e serviço social após realização de estudo psicossocial. Destas somente foi possível avaliar 77, devido à falta de acesso a todas as pastas após o despacho do juiz. Do total analisado, somente foram cumpridas 17 (22\%) das medidas protetivas determinadas, ao passo que 58 (75\%) não o foram e 2 (2\%) o foram apenas parcialmente.

Em contato com as instituições demandadas para o cumprimento das medidas protetivas, as respostas obtidas envolveram: a instituição recebeu o ofício, porém não realizou a ação demandada (8); o prontuário não foi encontrado (7); a família não compareceu/aderiu por falta de recursos financeiros (6); a família continua na lista de espera, após um ano de encaminhamento (6); o caso foi reencaminhado para outra instituição, que, por sua vez, afirmou não ter recebido o ofício (6); não foi recebido o ofício demandando a execução das medidas protetivas (5); falta de profissionais e alta demanda (4); o agressor retornou à residência, mesmo depois de ter recebido medida de afastamento (Art. 130) (Brasil, 1990) (2); a criança foi abrigada (2); foi realizado apenas um primeiro contato com a família (1); a família não compareceu por medo do agressor (1); mudança de gestão da instituição (1). Ressalta-se que algumas instituições apresentaram mais do que uma justificativa para o não cumprimento das medidas aplicadas, totalizando o número de 49 justificativas para 16 instituições consultadas, conforme relatado na seção "Método".

\section{Considerações Finais}

Embora este estudo não tenha intenções generalizantes, ele permite concluir que os dados encontrados refletem a realidade e poderão auxiliar as instâncias jurídicas e psicossociais a repensarem seus acompanhamentos. Conclui-se que a $1^{\text {a }}$ VIJ não conseguiu cumprir sua missão de garantir os direitos dessas 47 crianças e adolescentes, nem assegurar condições para seu pleno desenvolvimento. As crianças e adolescentes dos casos avaliados não receberam da $1^{\text {a }}$ VIJ a garantia de proteção integral, na medida em que o Poder Judiciário necessita de parcerias no Poder Executivo e na sociedade para fazer valer sua missão. Perde-se, assim, a essência do trabalho jurisdicional e a proposta do sistema de proteção e garantia de direitos, uma vez que ele fica restrito e limitado ao processo legal e burocrático, e deixa de se efetivar no mundo social e real.

Não se pode afirmar que a falha esteja nessa ou naquela instituição. Considera-se que as falhas se encontram na forma como funciona o sistema de enfrenta- 
mento à violência sexual e no relacionamento entre as instituições, ou melhor, na falta de relacionamento. A falha pode estar em não se reconhecer que o fenômeno da violência sexual ocorre com muito mais frequência do que aparenta e que o sistema de enfrentamento não tem acompanhado a crescente notabilidade que o fenômeno vem ganhando, demandando campanhas educativas e esclarecedoras, além de maior abertura da Justiça para a sociedade, de modo a favorecer a busca por proteção.

Além disso, desde o início da década de 1990, o Estado vem promovendo campanhas de incentivo à denúncia, o que é um passo importante no combate à violência sexual. No entanto, o Estado falha quando não oferece ao denunciante o devido suporte para enfrentar a crise que se segue após a denúncia. Não basta denunciar para que a violência sexual seja interrompida; outras violências eclodem e é necessário que a sociedade e o Estado estejam preparados com instituições fortes e eficazes para combatê-las também.

Os dados obtidos apontam ainda a falta de entendimento do que seja o trabalho em rede, o que explica os insucessos de uma rede que se diz rede, mas que não tem um padrão de organização de rede. Conforme Sanicola (2008), a rede se faz realizar pela troca constante de informações, é nessa relação que se pode conhecer e se deixar conhecer, revelando as insuficiências da rede e apontando caminhos alternativos para a resolução das falhas encontradas. No atual sistema de enfrentamento à violência sexual, cada membro faz o que pode, e espera que o outro também o faça. No entanto, essa forma de relacionamento profissional e institucional apresenta falhas, conforme se pode verificar com os dados da pesquisa, esgotando e exaurindo os próprios profissionais que se empenham no exercício de sua função. Pior ainda, tem-se revelado ineficaz no processo de proteger e atender as pessoas envolvidas em situação de violência sexual.

Os resultados obtidos revelaram que a Justiça da Infância e Juventude pode se encontrar de mãos atadas no que se refere ao cumprimento de suas decisões, uma vez que depende de outras instâncias para isso. Revelaram, também, que o processo legal de proteção integral se perde no fluxo da rede de enfrentamento à violência sexual e que seu trabalho de prestação jurisdicional cai no vazio da falta de relacionamento entre a Justiça e as outras instituições que acolhem, ou que pretendem acolher, as pessoas em situação de violência.
A falta do Estado em todo esse processo deve ser ressaltada. Os governos deixam suas instituições e seus servidores à deriva por falta de recursos financeiros, logísticos, humanos e pela falta de capacitação. Nos contatos da primeira autora com outros profissionais do sistema de enfrentamento à violência, estes relatam que os Centros de Referência de Assistência Social acumulam funções e tarefas sem o aumento correspondente de seus recursos; conselheiros tutelares são eleitos sem conhecimento adequado das questões da infância, da adolescência e/ou da família e assumem a tarefa de administrar o caos de semelhante falta de recursos; hospitais contam com poucos servidores e enfrentam dificuldade em estender suas ações preventivas e de tratamento psicológico à comunidade, também pela falta de recursos.

Se, por um lado, a Justiça não tem podido contar com a eficiência das instituições, estas também se queixam de que não podem contar com a Justiça, ressentindo-se da falta de acesso ao magistrado ou ao sistema legal. Queixam-se também da burocracia, que exige procedimentos protocolares para soluções simples ou para denúncias imediatas. Conclui-se, com isso, que o esgotamento presente nas situações de violência sexual se reproduz nas instituições de enfrentamento do fenômeno.

O sistema de enfrentamento também reproduz o padrão de relacionamento da situação abusiva, sendo marcado pelo isolamento, pelo silêncio e pela impotência. Esses são sinais de um sistema tão fragilizado quanto o sistema familiar em que ocorre a violência sexual. Para a sociedade, o resultado é a desproteção das pessoas em situação de violência sexual, o descrédito e a desqualificação das instituições sociais e a anulação das ações que se perdem na rede.

A proposta do estabelecimento de um trabalho orientado pelo padrão de organização de rede é uma alternativa que visa impedir a revitimização. A revitimização não é um conceito vazio. Ela foi demonstrada na presente pesquisa, que revelou que na maioria dos casos a vitimização é ocasionada pela falta de cumprimento das medidas protetivas, ou pela adoção de procedimentos independentes e desconexos. Os dados revelam que o atual sistema de enfrentamento e a atual metodologia impossibilitam a abordagem do problema de forma abrangente, tanto no que se refere às questões práticas (como saúde, proteção da criança/ adolescente, processo de responsabilização e tratamento do abusa- 
dor, dentre outras) como no que se refere à compreensão do fato em sua complexidade.

Os dados da pesquisa foram apresentados ao magistrado e aos servidores da 1 a VIJ e forneceram elementos que corroboraram a necessidade de se estabelecer uma nova metodologia de trabalho. Os resultados aqui obtidos culminaram com a criação do Centro de Referência para a Proteção Integral da Criança e do Adolescente em Situação de Violência Sexual, em julho de 2008. O Centro de Referência tem a função de assessorar o magistrado, por meio da realização de estudo psicossocial dos casos de violência sexual que tramitam na $1^{\text {a } ~ V I J . ~ N o ~ e n t a n t o, ~ i n d o ~ u m ~ p a s s o ~ a l e ́ m ~ d o ~ c u m p r i-~}$ mento dessa função, o Centro de Referência assume a tarefa de acompanhar as famílias durante seu percurso na rede institucional, no intuito de garantir que elas efetivamente tenham acesso ao atendimento básico de saúde e assistência social, entre outros - condições consideradas necessárias para o fortalecimento de suas competências, o resgate de sua autonomia e a interrupção do ciclo de violência e revitimização. Para esse acompanhamento, o Centro de Referência se propõe a realizar um trabalho de parceria e apoio mútuo com as instituições demandadas, assim como a inclusão da família na tomada de decisões e encaminhamentos realizados.

A proposta do trabalho de rede não tem a pretensão de ser a solução definitiva para a escassez de recursos do sistema de enfrentamento à violência, mas propõe-se a dirimir essa falta. Assim, o Centro de Referência se propõe a conglomerar o maior número de instituições - governamentais e da sociedade - para participar da Rede de Proteção Integral às crianças e adolescentes envolvidos em situação de violência sexual. Busca também favorecer e propiciar a intercomunicação das instituições-membro da Rede de Proteção Integral, de modo a garantir uma forma articulada, conexa e complementar de ações interventivas que impeçam a revitimização dos envolvidos. E, por fim, pretende favorecer a troca de conhecimento, práticas e informações entre os profissionais que fazem parte do sistema de enfrentamento à violência sexual.

\section{Referências}

Amaro, S. (2003). Crianças vítimas de violência: das sombras do sofrimento à genealogia da resistência, uma nova teoriacientífica. Porto Alegre: EDIPUCRS.
Azambuja, M. R. F. (2004). Violência sexual intrafamiliar: é possível proteger a criança? Porto Alegre: Livraria do Advogado.

Azevedo, M. A., \& Guerra, V. N. (1997). Infância e violência doméstica: fronteiras do conhecimento. São Paulo: Cortez.

Brasil. Lei $n^{\circ}$ 8.069, de 13 de julho de 1990. Estatuto da criança e do adolescente. Brasília: Senado.

Brasil. (1988). Constituição da República Federativa do Brasil. Brasília: Senado Federal, 1988.

Capra, F. (2004). A teia da vida: uma nova compreensão científica dos sistemas vivos. São Paulo: Cultrix.

Costa, L. F., Penso, M. A., Rufini, B., Mendes, J. A. A., \& Borba, N. (2007). Família e abuso sexual: silêncio e sofrimento entre a denúncia e a intervenção terapêutica. Arquivos Brasileiros de Psicologia. Recuperado em outubro 15, 2008, disponível em <http://146.164.3.26/seer/lab19/ojs2/ index.php/ojs2/article/view/105/109>.

Faleiros, E. (Org.) (2003). O abuso sexual contra crianças e adolescentes: os (des)caminhos da denúncia. Brasília: Presidência da República.

Faleiros, V. P., \& Faleiros, E. T. S. (2001). Circuito e curtos-circuitos: atendimento, defesa e responsabilidade do abuso sexual contra crianças e adolescentes no Distrito Federal. São Paulo: Veras.

Furniss, T. (1993). Abuso sexual da criança: uma abordagem multidisciplinar, manejo, terapia e intervenção legal integrados. Porto Alegre: Artes Médicas.

Habigzang, L. F.; Koller, S. H.; Azevedo, G. A., \& Machado, P. X. (2005). Abuso sexual infantil e dinâmica familiar: aspectos observados em processos jurídicos. Psicologia: Teoria e Pesquisa, 21 (3), 341-348.

Lamour, M. (1997). Os abusos sexuais em crianças pequenas: sedução, culpa, segredo. In M. Gabel (Org.), Crianças vítimas de abuso sexual (pp.43-61). São Paulo: Summus.

Nogueira, S. E., \& Sá, M. L. B. P. (2004). Atendimento psicológico a crianças vítimas de abuso sexual: alguns impasses e desafios. In M. C. C. A. Prado (Coord.), O mosaico da violência (pp.47-102). São Paulo: Vetor.

Rouyer, M. (1997). As crianças vítimas: conseqüências a curto e médio prazo. In M. Gabel (Org.), Crianças vítimas de abuso sexual (pp.62-71). São Paulo: Summus.

Sanderson, C. (2005). Abuso sexual em crianças. São Paulo: M. Brooks do Brasil.

Sanicola, L. (2008). As dinâmicas de redee o trabalho social. São Paulo: Veras.

Save the Children \& Suécia na América Latina e o Caribe. (2005). Estudo analítico do enfrentamento da exploração sexual comercial de crianças e adolescentes no Brasil-ESCCA: período 1996-2004. Rio de Janeiro: Autor.

Recebido em: 3/4/2009

Versão final reapresentada em: 24/11/2010

Aprovado em: 12/4/2011 